\section{BRE: A conversational program for bivariate regression and eta}

\author{
RONALD E. ANDERSON \\ Department of Sociology, University of Minnesota \\ Minneapolis, Minnesota 55455
}

Description. The regression program described here is unique in that it is a small self-contained package that also calculates eta (the correlation ratio), one-way analysis of variance, a graph of the group means. and provides for limited data manipulation capability such as recoding. The organization and structure of the program is oriented totally to conversational interaction; it is designed for use in timesharing or on-line environments. The mix of statistical and data tasks that are available within the program suggest three major uses: (1) detection of nonlinear relationships by comparison of eta with the linear regression of $x$ on $y,(2)$ exploration of the impact of coding/recoding of variable $x$ upon the calculation of eta and the one-way analysis of variance, and (3) computation of a monotonic variant of the correlation ratio (see Leik \& Gove, 1969). Leik and Gove show how Eta can be interpreted as an index of monotonicity. but only when the group means are monotonic and the group variances are homoscedastic. The recoding feature of the BRE program provides the potential for rearranging the $x$ variable coding so as to achieve monotonicity.

The following commands or action requests are available: (1) HELP: Instructions for conversational use are printed. (2) ETA: Both the bivariate regression and eta are computed for any pair of $x y$ variables. Eta, also called the "correlation ratio," is calculated as specified in common statistical texts (e.g., Anderson \& Zelditch, 1968: Edwards. 1970; Hays, 1973; Kerlinger, 1973; Loether \& McTavish, 1974; McNemar, 1962; \& Mueller, Scheussler, \& Costner, 1970). The algorithm involves sorting on $\mathrm{x}$ before the mean of $y$ is computed for each group on $x$. The mean and other statistics are printed for each group so the printout is extensive when there are many categories or groups on $x$. A graphical display of the group means and variances is optional. (3) LIST: Any number of cases of the data matrix are printed. This is especially useful to check on the effects of recoding. (4) RECODE: Values on any variable are collapsed or recorded. A range of values can be assigned to a single new value. The specified changes are made on the data matrix stored in central memory. (5) DATA: This comman restores the original condition of the data matrix by recopying the data from external storage to central memory. The feature is especially useful when the desired recoding requires returning to the original coding of the variables. Use of this feature will erase all prior modifications of the data. (6) STOP: Execution of the program is terminated.

Program and computer. The program is written in ANSI standard FORTRAN except for the designation of Hollerith character strings for output. Although it was designed to run on a PDP $8 / E$ as well as larger systems which support FORTRAN IV, it now runs under KRONOS 2.1 on a CDC CYBER 72.

Availability. A listing and write-up of the program are available at no cost; either a punched card deck or a punched paper tape are available for a charge of $\$ 10$. Requests should be directed to Ronald E. Anderson, Department of Sociology, University of Minnesota, Minneapolis, Minnesota 55455.

\section{REFERENCES}

Anderson, T. R., \& Zelditch, T. R. $A$ basic course in statistics (2nd ed.). New York: Holt, Rinehart, and Winston, 1968. Pp. 155ff.

EDwards, A. Statistical methods (2nd ed.). New York: Holt, Rinehart, and Winston. 1970. Pp. 136ff.

Hays, W. L. Statistics for the Social Sciences (2nd ed.). New York: Holt, Rinehart, and Winston, 1973. Pp. 683-684.

KERLINGER, F. N. Foundations of behavioral reseanch (2nd ed.). New York: Holt, Rinehart, and Winston, 1973. Pp. 633-634.

LEIK, R. K., \& Gove, W. R. The conception and measurement of asymmetric monotonic relationships in sociology. American Journal of Sociology, 1969, 74, 969-709.

LOETHER, H., \& MCTAvish, D. G. Descriptive statistics for sociologists. Boston: Allyn and Bacon, 1974. Pp. 248-251.

McNemar, Q. Psychological statistics (3rd ed.). New York: Wiley, 1962. P. 202.

Mueller, J., Schuessler, K., \& Costner, H. Statistical reasoning in sociology (2nd ed.). Boston, Massachussets: HoughtonMifflin, 1970. Pp. 325ff. 